\title{
Elementos de los estudios visuales: un análisis crítico de la mirada desde el esencialismo visual a los regímenes escópicos
}

\section{Fernando Ramón Contreras-Medina ${ }^{1}$}

Recibido: 2017-07-13

Enviado a pares: 2017-08-01
Aprobado por pares: $2017-10-01$

Aceptado: 2017-10-10

DOI: 10.5294/pacla.2018.21.4.10

Para citar este artículo / to reference this article / para citar este artigo

Contreras-Medina, F. R. (2018). Elementos de los estudios visuales: un análisis crítico de la mirada desde el esencialismo visual a los regímenes escópicos. Palabra Clave, 21(4), 1189-1213. doi: 10.5294/pacla.2018.21.4.10

\section{Resumen}

El objetivo de este artículo es el examen de aquellos elementos integrantes de los estudios visuales que nos ofrecen una visión nítida sobre los regímenes escópicos desde el origen de la modernidad. La investigación analiza este fenómeno de la cultura visual provocado por las innovaciones tecnológicas y los avances científicos, las corrientes ideológicas y la propia influencia de la herencia cultural y filosófica del pasado. La metodología de esta investigación de carácter teórico se basa en el enfoque interdisciplinar de los estudios visuales. El conocimiento de lo visual avanza desde la hermenéutica a la teoría crítica, en busca de la comprensión desde la interdisciplinariedad (que incluye las disciplinas tradicionales como la teoría del arte, historia del arte y estética). Entre los resultados conseguidos destacamos la definición de los conceptos más importantes para los estudios visuales: la cultura visual, los objetos visuales, el esencialismo visual y los regímenes escópicos. En las conclusiones, subrayamos la liberación de la textualidad

1 orcid.org/0000-0003-1105-5800. Universidad de Sevilla, España. fmedina@us.es 
que experimentan las imágenes en la cultura contemporánea. Lo visual se presta a las interpretaciones que bajo sus hábitos de vida ahora trazan los espectadores. La vivencia de las imágenes queda supeditada a la mirada de la ciencia o de las creencias e ideologías de aquellos individuos que pertenecen a una cultura concreta. El artículo ofrece una visión innovadora al revelar las reglas establecidas por los regímenes escópicos y lo que caracteriza un modo determinado de contemplación del mundo (una manera determinada de mirar) a partir de las formas de vida de sus actores.

\section{Palabras clave}

Visualización, artes visuales, material visual, estética, comunicación (Fuente: Tesauro de la Unesco). 


\section{Elements of Visual Studies: A Critical Analysis of Scopic Regimes Seen from the Standpoint of Visual Essentialism}

\section{Abstract}

The objective of this article is to examine the integrating elements of visual studies that offer us a clear vision of scopic regimes ever since the origin of modernity. The research analyzes this phenomenon of visual culture caused by technological innovations and scientific advances, ideological currents of thought, and the influence particular to the cultural and philosophical heritage of the past. The methodology of this theoretical research is based on the interdisciplinary approach of visual studies. Knowledge or comprehension of the visual progresses from hermeneutics to critical theory, in search of understanding through interdisciplinarity (which includes traditional disciplines such as art theory, history of art and aesthetics). Among the results, the authors define the most important concepts visual studies; namely, visual culture, visual objects, visual essentialism and scopic regimes. In the conclusions, they emphasize the liberation of textuality that images experience in contemporary culture. The visual lends itself to interpretations that now delineate or define spectators according to their living habits or lifestyles. The way images are experienced is subject to the gaze of science or the beliefs and ideologies of those individuals who belong to a specific culture. The article offers an innovative view by revealing the rules established through scopic regimes and what characterizes a particular way of contemplating the world (a certain way of looking at things) based on the different ways of life of its actors.

\section{Keywords}

Visualization; visual arts; visual material; aesthetics; communication (Source: Unesco Thesaurus). 


\section{Elementos dos estudos visuais: uma análise crítica da visão desde 0 essencialismo visual até os regimes escópicos}

\section{Resumo}

O objetivo deste artigo é analisar aqueles elementos integrantes dos estudos visuais que nos oferecem uma visão nítida sobre os regimes escópicos a partir da origem da modernidade. Esta pesquisa analisa esse fenômeno da cultura visual provocado pelas inovações tecnológicas e pelo progresso científico, pelas correntes ideológicas e pela própria influência da herança cultural e filosófica do passado. A metodologia desta pesquisa de caráter teórico baseia-se na abordagem interdisciplinar dos estudos visuais. $\mathrm{O}$ conhecimento do visual avança desde a hermenêutica até a teoria crítica, em busca da compreensão a partir da interdisciplinaridade (que inclui as disciplinas tradicionais como a teoria da arte, a história da arte e a estética). Entre os resultados, destacamos a definição dos conceitos mais importantes para os estudos visuais: a cultura visual, os objetos visuais, o essencialismo visual e os regimes escópicos. Nas conclusões, destacamos a liberação da textualidade que as imagens experimentam na cultura contemporânea. $O$ visual serve para interpretações que, sob seus hábitos de vida, agora estabelecem os espectadores. A vivência das imagens fica subordinada ao olhar da ciência ou das crenças e ideologias daqueles indivíduos que pertencem a uma cultura concreta. Este artigo oferece uma visão inovadora ao revelar as regras estabelecidas pelos regimes escópicos e o que caracteriza um modo determinado de contemplação do mundo (uma maneira determinada de olhar) a partir das formas de vida de seus atores.

\section{Palavras-chave}

Visualização, artes visuais, material visual, estética, comunicação (Fonte: Tesauro da Unesco). 


\section{Introducción: nuevos conceptos de los estudios visuales}

Cuando Norman Bryson (2005) mira la pintura de naturalezas muertas, además de contemplar una obra de arte, concibe en este acto como un modelo de análisis visual. De su modo de mirar parece desprenderse que leer visualmente es una cuestión comparativa entre el arte y la teoría crítica. A esta conclusión se llega cuando Bryson antepone en sus análisis los gestos del artista frente a la disposición de los objetos en la pintura. Esta operación pretende mostrar otra oposición entre el espacio pictórico y el espacio mundano intensificado hasta alcanzar la teatralidad y la hiperrealidad. En su exposición sobre el bodegón, nos demuestra cómo a través del espacio pictórico el artista domina los espacios sociales o aquellos propios de la privacidad de los hombres. El bodegón no es exclusivamente un discurso de maestría que rehúsa su contacto con la realidad social. Además, es un discurso microhistórico a través del cual conocemos la vida cotidiana de los hombres que vivieron en el mismo tiempo de la concepción de la obra. El bodegón debe aislarse de su particularidad que es su esencia, para que de su abstracción alcancemos los detalles y formemos ideas generales. A nuestro juicio, Bryson es el autor que más claramente nos muestra los dos polos opuestos del análisis visual comprendidos entre el estudio del esencialismo visual y la investigación de los regímenes escópicos. En su estudio sobre la pintura de naturalezas muertas y el espacio femenino, ya delimita el concepto de régimen escópico como una construcción del poder de la visión y la fuerza política de la cultura visual:

Las palabras de Shaftesbury indican dos modos diferentes de visión, divididos entre los sexos desde el nacimiento: para el varón, visión conforme a la abstracción, elevándose sobre el simple detalle y el reclamo sensorial para alcanzar una vista de conjunto; para la hembra, visión ajustada al detalle sensual y las superficies del mundo, color, textura, ricas telas y sedas. (p. 185)

El análisis de Bryson presenta la pintura de naturalezas muertas como construcciones discursivas que exhiben la autoridad de la masculinidad. Mediante las cualidades visuales de los objetos (dureza/ elasticidad, vasto/ suave, poderoso/tierno, vasto/elegante, etc.) se opera de un modo deter- 
minado de visión que le está proscrito al sujeto masculino. Cuando estas construcciones se llevan a sus límites (el trabajo de casa es de las mujeres como la extracción del agua de un pozo o hacer la compra en un mercado), la pintura y el espacio cotidiano a través de la representación de los gestos corrientes de la vida condicionan las normas internas de las sociedades.

Finalmente, queremos puntualizar que este artículo, más que presentar resultados novedosos de investigación, propone una revisión bibliográfica que nos aproxima a la cuestión de los estudios visuales. Por ello, su aportación más singular consiste en procurar al lector un horizonte vasto, identificando cuáles son los problemas centrales del área en el contexto contemporáneo.

\section{Contra el método: volver a mirar}

Volver a mirar es, pues, un enfoque distinto que distingue al análisis visual de las disciplinas convencionales, la estética, la teoría del arte, la crítica del arte e incluso de la historia del arte, aunque no excluye ninguna de estas disciplinas de su metodología interdisciplinar. En el análisis cultural (en nuestro caso, además análisis visual), filosófico y humanista, cada vez cobra mayor importancia la interdisciplinariedad. La multiplicidad de los saberes que el análisis visual entrecruza en su discurso requiere una coherencia interna (unidad, relación y reciprocidad entre distintas ramas del conocimiento) para que realmente la investigación avance en el desarrollo cultural y social de la comunidad. No obstante, esto supone un salto epistémico de la visión institucional del método, como ya expresó Feyerabend (2003). La polémica del análisis visual comienza con sus postulados hermenéuticos que ofrecen más comprensión que una explicación científica de la obra visual. El análisis visual, junto con los principios de la teoría crítica, busca en la investigación la comprensión de la sociedad, no la consolidación de sus instancias e instituciones mediante la aplicación de la racionalidad instrumental. De ahí su naturaleza emancipadora, cuyo funcionamiento coloca bajo sospecha la composición informal o la mirada periférica sobre las imágenes en lienzo o en la pantalla. En el análisis visual, la lógica de inferencia del conocimiento, en la mayoría de los casos, combina lo inductivo con lo deductivo. De esta manera, concierta el sentido del estudio desde los he- 
chos particulares a los generales (inducción), pero también puede comenzar en sentido contrario (deducción). La presente investigación se vale de estos recursos metodológicos, y de una revisión minuciosa de textos seleccionados (Bal, 2003; Bergson, 2006; Boehm 2011a; Bryson, 2005; Crary, 2008; Croce, 1938; Danto, 2014; Dickie, 2005; Greenberg, 2005; Goodman, 1990; Jay, 2007; Merleau-Ponty, 2013; Mitchell, 2011a; Rancière, 2010) que han sido estudiados para describir la travesía entre el esencialismo visual y los regímenes escópicos.

Todo ello conlleva una dificultad, pues, en esta revisión sobre la visualidad, es imposible mantener el carácter distintivo de cada disciplina o corriente filosófica. No pretendemos demostrar una fraternidad ilícita entre pensadores que dialogan con otros. Más bien deseamos llamar la atención sobre las relaciones alternantes de prioridad entre el pensamiento crítico y el análisis cultural visual. La densidad de las ideas centrales (esencialismo visual, regímenes escópicos) nos ha venido dada desde la estrecha relación, a veces providencial, entre las diversas teorías del arte, la estética, la historia del arte y, actualmente, los estudios visuales. La interpretación posmoderna del arte no tiene una conclusión narrativa y, por tanto, argumentativa. El deseo de representación del mundo proporciona el contrapunto perfecto a las críticas que resaltan lo ilegítimo de la interdisciplinariedad o, en nuestro caso, la desenfrenada libertad del investigador de la visualidad contemporánea. El proyecto romántico de superación del arte en la posmodernidad transfigura la imagen en un objeto vivo, cuya existencia pierde esencia en una expropiación radical de su significación intersubjetiva. La complejidad ecléctica de lo visual nos obliga inevitablemente a enfrentar voces que nos llegan de periodos distintos de la historia y de paradigmas epistémicos opuestos. Cada vez más, mirar los efectos de la posmodernidad en el estudio de lo visual viene a retratar la investigación como actividad autorreflexiva con la enjundia necesaria para reconocer su discurso autovalorativo ( $y$ también soberbio).

\section{La cuestión del valor revolucionario de la cultura visual}

Hablamos de cultura visual tras la desilusión posmoderna que experimentamos frente a la veracidad de los sistemas de representación visual. La 
posmodernidad abarca también un periodo crítico para el arte. La ruptura con los metarrelatos en este periodo, como ha explicado Lyotard (2012), ha dejado también bajo sospecha al arte como discurso legítimo institucional. La crisis del arte también ha supuesto la crisis de la representación en su más extenso sentido. Quizá como ha expresado Virilio (1989), todo esto sucede como consecuencia de la inflación de imágenes que experimentamos desde la mecanización de la visión. La producción masiva de los medios de comunicación y su consumo intensivo con la multiplicación de pantallas ha devaluado el valor de la imagen. Aunque este razonamiento sería la explicación más obvia desde una perspectiva social, también caben los planteamientos de una crisis contemporánea del arte bajo la teoría institucional de Dickie: "Una obra de arte en sentido clasificatorio es 1) un artefacto y 2) un conjunto de cuyos aspectos le ha conferido el estatus de ser candidato para la apreciación por alguna persona o personas que actúan de parte de una cierta institución social (el mundo del arte)” (2005, p. 18).

Desde el ámbito de la teoría, Dickie dará fin a la metafísica del arte con esta afirmación. El arte ya no es más que otro valor de intercambio en el mercado de la plusvalía, es decir, a través del valor simbólico que adquiere la obra por los intereses humanos en el mundo del arte. Sin embargo, el sentido de propiedad del arte no será el único que cuente para diferenciar una obra de lo que no es arte. La crítica de Greenberg (2005) se dirige hacia la pérdida de las cualidades específicas del arte. Greenberg llega a esta conclusión a través de Benjamin (1992) cuando explica la falta de originalidad que ha causado la producción masiva de los medios de reproducción técnica. El final del aura de la originalidad del autor supone el final de la autenticidad de la obra que ya no se inscribe en la historia, y que además enaltece la copia que no difiere visualmente del original. Greenberg afirmará que, si el arte clásico consistió en la imitación de la naturaleza, tras las vanguardias artísticas el arte es una imitación de la imitación. Para las vanguardias artísticas no es relevante la conexión con la naturaleza. Abandonando el concepto de mímesis, la originalidad es comprendida como la introducción de lo nuevo en el devenir histórico. El arte ya no representa esa unidad armoniosa y equilibrada que siempre se mostró entre el hombre y la naturaleza. Heidegger (2012) reconocía que el arte era la posibi- 
lidad técnica (téchnē) de relacionarse con la originalidad, es decir, con la misma naturaleza: "Desde el momento en que la obra levanta un mundo, crea la tierra, la trae aquí. Debemos tomar la palabra para crear en su sentido más estricto, como traer aquí. La obra sostiene y lleva a la propia tierra a lo abierto de un mundo. La obra permite a la tierra ser tierra" (las cursivas son mías) (Heidegger, 2012, p. 33).

Las vanguardias artísticas cambiarán con esta empatía mimética hacia la naturaleza en favor del progreso industrial y tecnológico que generará innovación en la creación de nuevos artefactos. Las vanguardias dominaron con el imaginario de la cadena de montaje de las fábricas fordistas americanas el diseño europeo y soviético, las grandes construcciones (rascacielos), la tecnología estadounidense, el diseño industrial o la publicidad. La cultura visual comienza con este encubrimiento de la imperfecta naturaleza y se inspira en la carrera por la creación de máquinas que crean máquinas para implementar un modelo industrial de producción. Ello tendrá otras consecuencias conocidas, como la dialéctica abierta entre lo urbano y lo rural, la periferia y el centro, la provocación de la apropiación o el flujo entre lo bajo a lo elevado de la que surgió el kitsch entre ganas de innovar. Colaboraron en estas transformaciones culturales el abandono de la modernidad homogeneizadora y el incremento de la complejidad de la identidad cultural. La crisis del arte y de los demás sistemas de representación desembocará en la exaltación de la hibridez, la mezcla, la impureza y la contaminación, resultado de numerosas combinaciones que provocan los nuevos fenómenos sociales (la inmigración), las diferentes concepciones de la vida y el mundo, la diversificación de las ideologías y los estilos visuales de la fotografía, de la cinematografía, así como el eclecticismo de la industria discográfica. Más que en otro lugar, fue en la antigua Unión Soviética donde más insistían en introducir el arte en la industria. Wollen (2006) nos enseña cómo las formas burguesas fueron eliminadas por los artistas y teóricos soviéticos, que prefirieron resaltar las afinidades del arte con la ciencia y la tecnología. El arte debía ser orientado hacia la producción. El sentimiento estético o la preocupación por la libertad creativa eran cuestiones ociosas de la clase burguesa. 
En Europa, André Breton (1896-1966) se opondrá al materialismo y al positivismo imperante e introducirá en la modernidad las ideas del Romanticismo, la teoría psicoanalítica, la defensa de la soberanía del arte, así como su especificidad y la independencia de la actividad artística. Surge de este modo un dualismo que privilegia la materia o la mente, los sueños o la vida cotidiana, el pluralismo textual de Barthes (1999) o el determinismo de Debord (2010), para el que la revolución poética tenía que ser una revolución política. La suma hizo emerger en movimientos artísticos como el surrealismo la combinación del Romanticismo y del activismo político libertario. El giro visual consistió en el viraje de un arte dionisíaco a un arte apolíneo. Abandonando el simbolismo mágico y la ornamentación, el arte se encamina hacia el diseño político, el arte público y la acción colectiva.

\section{La naturaleza del objeto visual}

La naturaleza del objeto visual ha sido el centro de debates, disputas y controversias respecto del conocimiento del arte $y$, en general, de la imagen. Desde distintas tradiciones filosóficas y científicas se han trazado aproximaciones muy diferentes sobre la naturaleza de las imágenes y de aquello que ahora denominamos objetos visuales.

En el conjunto de estas teorías, Moxey (2015) ha querido encontrar una división marcada por los teóricos norteamericanos y los intelectuales europeos, pero también denominadores comunes entre ellos. Las correspondencias abiertas entre Mitchell (2011b) y Boehm (2011b) es una prueba de estas conexiones. Por otro lado, parece que la diferencia fundamental radica en el modo de acercamiento a la imagen que puede concebirse como "representación" o "presentación".

La historia del arte y los estudios visuales en el Reino Unido y los Estados Unidos han tendido a plantear un acercamiento a la imagen concebida como representación, construcción visual que traiciona la motivación ideológica de sus creadores y cuyo contenido es susceptible de manipulación por parte de sus receptores. Por el contrario, el enfoque contemporáneo que atiende la presencia del objeto visual, cómo este interacciona con el espectador desviándose de los programas culturales para los que fue con- 
cebido y que nos afecta de un modo que los sistemas de signos no pueden regular nos invita a considerar el estatus de la imagen como presentación (Moxey, 2015, pp. 99-100).

El planteamiento de Boehm difiere precisamente en la materialidad existencial que les otorga a las imágenes (Bild), que, de este modo, adquieren su condición de objeto con vida independiente. Para ello, Boehm (2011b) explica en qué consiste su "giro icónico" frente a la concepción de "giro pictorial" de Mitchell (2011b). Boehm (2011a), haciendo acopio de las ideas filosóficas de Nietzsche y Wittgenstein, sostiene que el signo lingüístico no es superior en certeza epistémica sobre el signo visual. Mientras que el lenguaje necesita estructurar la información bajo el paradigma epistémico lineal, secuencial y ordenado bajo las reglas de la lógica, las imágenes comunican su significado también bajo el paradigma cosmogónico (platónico), mostrando en numerosas ocasiones la totalidad del sentido desde el principio y organizando sin un tiempo lineal la idea y su subjetividad. Podemos también alcanzar esta conclusión, a través del estudio de Pinotti (2017) sobre el principio fundamental legal de audire alteram partem que Wickhoff (citado en Pinotti, 2017) encuentra en la representación de juicios y escenas de debates o discusiones controvertidas. En estas, la figura central se muestra dialogando simultáneamente en dos direcciones en el mismo espacio. El ejemplo que señala para su argumentación es la ilustración del manuscrito Der Sachsenspiegel. "Bilder aus der Heidelberger Handschrift, eingeleitet und erläutert von Eberhard Freiherr von Künssberg, Insel Verlag, Leipzig 1934” (Pinotti, 2017, pp. 50-51).

En el giro pictorial, ya Mitchell (2011a) establece una diferencia entre las imágenes que considera un tipo especial de signo, "algo similar a un actor en un escenario de la historia, una presencia o un personaje imbuido de un carácter legendario, una historia paralela que participa de los relatos que nos contamos sobre nuestra propia evolución” (p. 109). Mitchell pretende desligarse de la tradición semiótica que se ocupaba del análisis de las imágenes mediante la lógica de las leyes lingüísticas. En su caso, las imágenes están unidas a todos los factores del proceso creativo desde las condiciones sociales a los factores tecnológicos. Además, añade que, una vez creadas, se 
independizan de su origen (como organismos vivos autónomos) y que parcialmente pueden ser controladas por sus creadores. Es fácil observar que Mitchell justifica todos estos cambios sobre la noción de imagen para referirse a los artefactos visuales (u objetos visuales) en el cambio cultural de la posmodernidad. Así también lo parece sugerir García Varas al recordarnos la influencia de Foucault sobre este historiador:

\begin{abstract}
Mitchell, por su parte, reconoce así mismo esta transformación en las formas de estudio cultural, entendida como un cambio de paradigma dentro de las disciplinas académicas, pero insiste además en que la misma no está tan lejos de los cambios de modelo retórico: aquello que Foucault denominaría un "tropo" o "figura de conocimiento". En su opinión, esta transformación de los modelos retóricos vendría de la mano de la creación de un nuevo repertorio de imágenes. (2011, p. 18)
\end{abstract}

Pese a las diferencias, sobre todo en las matizaciones sobre la cuestión, en el marco teórico de los estudios visuales, existe el acuerdo de la superación del giro lingüístico, a través de un giro hacia las imágenes, en cuyo conjunto se incluyen desde aquellas que no abarca el arte hasta las imágenes nuevas (fotografía, cine o la síntesis digital) y aquellas que no tienen origen en las tecnologías (recuerdos sueños, ideas). Por su parte, sobrepasar el giro lingüístico ha sido una importante transformación cultural que caracteriza este momento presente. Básicamente, lo que se postula nuevo es el acceso al mundo sin la mediación del lenguaje, revalorizar la "presencia” frente al significado de las cosas. El arte tiene la posibilidad de ofrecer objetos que el espectador encuentra, y sobre los que los significados atribuidos no controlan su sentido. De este modo, podemos frente a una imagen ir más allá de su interpretación semiótica, y encontrar cómo se desafía al entendimiento. Gumbrecht (2004), citado en Moxey (2015), destaca por su planteamiento radical de aproximación a lo real mediante la percepción en detrimento del lenguaje. El hombre se ha rodeado de un mundo saturado de signos formando capas de sentido que condicionan nuestras vidas y determinan nuestras actitudes. Gumbrecht defiende las interpretaciones de la experiencia frente a las interpretaciones de los significados. Desde este razonamiento, lo que se prioriza es la vida de los objetos frente al agotamiento de la confianza en los regímenes de representación; como afirma 
Moxey (2015, p. 99), "reclama interpretaciones tan sensibles a los efectos de la presencia como lo son a los efectos del significado".

\section{El esencialismo visual}

El esencialismo visual surge de la búsqueda de los objetos visuales, y encontrarlos le supone al hombre pensar dando prioridad a la percepción sobre la comprensión o el juicio. La percepción de los objetos visuales se ha traducido a veces como una fenomenología del tacto. La tactibilidad de la materialidad es una parte de la visualidad de los objetos. Esa tactibilidad le confiere el valor de real que sobrepasa la construcción discursiva de "realidad" de las cosas. En este sentido, el esencialismo visual debería entenderse como la intensificación de la experiencia frente a la materialidad de estos objetos visuales. Otra interpretación por meditar es la concepción de esencia visual como la percepción de la apariencia de los objetos. Desde esta perspectiva, aceptaremos que la superficie de los objetos condiciona su significado. Finalmente, conviene apuntar que lo visual en cuanto fenómeno humano también es una cuestión social; supone además una interpretación bajo las condiciones ideológicas de los regímenes escópicos.

La moderna investigación en neuroestética (Pombo, Di Marco y Pina, 2010) también se debate entre estos límites. Básicamente, viene a mostrarnos que la comprensión de lo visual no depende exclusivamente de las evidencias empíricas, sino más bien de una explicación dividida entre lo que nos ofrece, por un lado, la ciencia y la tecnología, y por el otro, la aportación de la filosofía de la percepción (Bergson, 2006) y de la fenomenología (Husserl, 2011). Desde su condición neurológica, lo visual analiza las preferencias en la percepción de los temas y los criterios que controlan el mundo como una unidad visual. En este sentido, Cappelletto (2010) considera que el arte es usado aquí como una metonimia que nos permite simplificar la concepción del mundo y, por tanto, de la realidad. Zeki (1999) parece sugerirnos sobre lo visual o más concretamente sobre la teoría de la experiencia humana artística y los mecanismos neuronales que intervienen: la presencia de divergencias con la estética. Frente a una escultura móvil de Alexander Calder (1898-1976), percibimos el movimiento, provocado por el viento, sin ver concretamente el color. Detrás de la visión en- 
contramos la ciencia que explica el mundo con respuestas sobre lo que es y lo que ocurre, en cambio, la estética se circunscribe a lo que puede ser y que pudiese suceder.

La ciencia y la filosofía, respetando las dos posiciones de la obra de arte, la creación y la conducta del público, se enfrentan a la controversia que supone la imagen percibida del objeto y la perfección de su definición conceptual. O bien, volviendo a lo expresado por Cappelletto (2010), nos encontramos frente a la polaridad del empirismo y del idealismo, como tradicionalmente se han denominado estas dos posiciones filosóficas. Esta controversia la descubrimos en la obra One and Three Chairs (1965), del artista americano Joseph Kosuth. El artista en su investigación sobre la naturaleza del arte presenta una obra que consiste en una silla, la fotografía de la silla y una definición impresa del diccionario. La silla frente al espectador es experimentada en un continuo presente, la fotografía de la silla es vivida en un tiempo pasado que fue cuando se realizó la imagen y la definición del diccionario nos lleva a pensar en el futuro, ya que la misma definición sobrevivirá al transcurso del tiempo. Por el contrario, la silla o la fotografía podrán desaparecer deterioradas. Además, somos conscientes de que la imagen fotográfica o con la definición del diccionario no percibimos la experiencia de la realidad; por otro lado, la definición de la silla solo nos ofrece una idea. Joseph Kosuth nos revela en su obra una tradición cognitiva que vincula el arte al conocimiento de la realidad. Por este empeño científico, Gombrich (2014) nunca abandonó su obsesión por la mímesis renacentista, por considerarlo un camino para equiparar el análisis del arte al estudio de la cognición humana. La misma idea persiguió Feyerabend en su Wissenschaft als Kunst (1984), cuando el arte adquiere un "significado realista". Para Feyerabend, el arte no se centra en una sola concepción de la realidad, sino que en su interior conviven pacíficamente distintas tradiciones de representación o de conocimiento del mundo. Los estudios en esta dirección continúan en Nelson Goodman (1976) cuando considera el arte como una parte integral de la epistemología. El arte es representación de la realidad, que no es lo mismo que su imitación. El arte refiere algo que no necesariamente tiene que existir o haber existido. Es una manera de crear otros mundos que no vemos, pero 
que si ha sido correctamente construido tiene por sí mismo la misma realidad que los restantes.

\begin{abstract}
Los mundos de la ficción, de la poesía, de la pintura, de la música o de la danza y los de las otras artes están hechos en gran medida de mecanismos no literales, tales como la metáfora, o por medios no denotativos tales como la ejemplificación y la expresión. $Y$ en esos mundos se acude también, con frecuencia, a imágenes, sonidos, gestos 0 a otros símbolos pertenecientes a sistemas no lingüísticos. Esas formas de hacer mundos y esas versiones son los que aquí nos ocupan de manera central, pues una de las tesis principales de este libro es que el arte no debe tomarse menos en serio que las ciencias en tanto forma de descubrimiento, de creación y de ampliación del conocer, en el sentido más amplio de promoción del entendimiento humano, y que, por tanto, la filosofía del arte debe concebirse como un parte integral de la metafísica y la epistemología. (Goodman, 1990, p. 141)
\end{abstract}

En el centro de todas estas cuestiones, hallamos la problemática de la esencia de la visualidad, que resumimos en los siguientes puntos: 1) encontrar en lo visible las verdaderas diferencias de la naturaleza o las articulaciones de lo real desde un enfoque bergsoniano; 2) la impureza de la visualidad, pues, como ha explicado Bal (2003), escuchar, leer, oler o saborear poseen grados de visualidad (estas cualidades se manifiestan en las actuales instalaciones artísticas); y 3 ) el rechazo al esencialismo visual en el mundo moderno, pues la visualidad es una nueva categoría epistémica que explica desde los fenómenos humanos a aquellos que pertenecen a la naturaleza.

Desde estos términos, se revela que el esencialismo visual ha consistido en aislar la visión respecto del conocimiento que procuraba otros sentidos. En su estudio, Jay (2007) explica que no siempre imperó la tiranía del noble sentido de la visión. Varias pruebas históricas, como el recurso luterano a la tradición hebraica de privilegio del oído o la antivisualidad medieval que defienden otros teóricos como Barthes (1997), sitúan la vista detrás del oído y después del tacto en sus preferencias sobre los sentidos perceptivos. Luego, durante el Barroco, el ojo fue el primer órgano de la percepción. Pese a esta tesis de una Edad Media ocularfóbica, Jay destaca la importancia de la imagen del speculum sine macula, cuyo valor simbólico se hizo imprescindible para la expansión del culto a la Virgen María y, 
en términos seculares, la recuperación del respeto a la tradición aristotélica de la observación durante el siglo XIII.

\section{La naturaleza de los regímenes escópicos}

Desde la concepción equivocada (en otros tiempos pasados aceptada) del esencialismo visual llegamos a los regímenes escópicos. Sucedió como lo explica Jay, la visión, tras su liberación de la función sagrada, comenzó con su propio desarrollo: "Las lecciones aprendidas sobre sus capacidades de persuasión nunca se olvidaron. De hecho, se aplicaron rápidamente con propósitos políticos y sociales" (2007, p. 42). El esencialismo visual buscaba las bondades de las imágenes, así Tomás de Aquino lo pretendió defender en su Summa al decir sensus magis cogniscitivus (citado en Jay, 2007, p. 39). Otra argumentación en favor del esencialismo visual revalorizaba la experiencia ocular frente al miedo a la idolatría religiosa, el impulso iconofóbico de la Reforma e incluso un incremento del interés por las artes sofísticas de la retórica durante el Renacimiento. Los regímenes escópicos comenzaron con el régimen ocular barroco que descubrió la función del orden visual dominante científico o racionalizado. Según apunta Jay, en este momento, ya podemos hablar de regímenes escópicos:

La cultura barroca surgió en conexión con la respuesta de la Iglesia católica al desafío del protestantismo, la revolución científica y las exploraciones del siglo XVII, por caminos demasiados complejos para detallarlos ahora. También acompañó y favoreció la aparición del Estado absolutista. Rechazando la sospecha de la Reforma sobre la visión y su única confianza en palabra directa de Dios, la Iglesia barroca, tras un momento de duda, recurrió conscientemente a la seducción sensual para volver a ganarse a las masas (tras obtener hasta cierto punto de éxito en este empeño en el siglo XIV). (pp. 42-43)

En el riguroso estudio de Jay sobre la visión se nos explica que, a partir del Barroco, las imágenes fueron desplegadas en los espectáculos seductores como táctica en la lucha por el poder contra las fuerzas sociales disruptivas. Los Estados autoritarios y centralizadores del poder de las monarquías absolutistas emplearon la fuerza de la visión frente a las posibilidades de la literatura. Los primeros regímenes escópicos cumplieron con rituales cortesanos. El poder de lo visual fue utilizado para la función política con el es- 
pectáculo cortesano. Sin embargo, pronto la confianza en la actitud visual, asumida en términos políticos y sociales, provocó la autonomía de lo visual, consiguiéndose un equilibrio entre la textualidad y la imaginería. Cuando las imágenes se independizaron de los significados textuales para adquirir su propio significado visual, se liberaron paulatinamente de su función narrativa. El proceso de desnarrativización desarrolló otras prácticas artísticas que organizaban el mundo visible al espectador, como, en el pasado, el universo fue ordenado por Dios. La construzione legittima (la perspectiva con dos puntos de fuga), el cuerpo del artista, la diferencia entre la mirada (gaze) y la idealizada ojeada corporal, la mirada del espectador al otro lado de la ventana que limitaba el marco de una pintura, la construcción del espacio teatralizado o los principios científicos que determinaban la perfección de la obra fueron algunas prácticas que surgieron de los regímenes escópicos. La irrupción de un nuevo poder visual desnarrativizado supuso el refinamiento de otros relatos visuales que separaban mundos sociales diferentes por la división del trabajo, el capitalismo, los estilos poéticos, las tendencias del consumo y los espacios de producción, causa de la disyunción radical entre los objetos del arte. Así, movido por el impulso de cartografiar el mundo social y las tensiones políticas, el poder de la visualidad fue utilizado para crear distancias entre los hombres. Ya en las primeras líneas de este estudio, comentábamos cómo Bryson demuestra que la pintura de la naturaleza muerta es dispuesta en el Barroco para la diferenciación social entre la masculinidad y la feminidad. Los regímenes escópicos adquirieron el sentido que Wittgenstein (1977) daba a su expresión Lebensform, solo pueden existir si se dan unas determinadas condiciones de vida. Para que se consolidaran los regímenes escópicos, también debían implementarse determinados órdenes políticos y sociales que establecieran formas de vida, de hábitos, de experiencias o de habilidades con la creación visual. La legitimación de la visión tuvo que ver con la implementación de modelos de producción (el industrialismo), la emergencia de ideologías (los nacionalismos), los modelos económicos (el capitalismo), la imposición de modelos universales de educación o la uniformización de las conductas mediante los planes de alfabetización (la alfabetización digital en nuestros días). La presencia de formas de vida implica la existencia de determinadas experiencias y que pueden identificarse independientes del lenguaje. 
El arte visual y su caracterización también como forma de vida adquiere ciertas implicaciones paralelas (Wollheim, 1972). Preguntándose el significado de la percepción, Bergson (2006) se planteará una cuestión similar sobre la posibilidad de una percepción modélica, o lo que es para nosotros el esencialismo visual, y discurrirá sobre la existencia de tipos de percepción y de atención que poseen determinadas posibilidades estéticas, éticas o políticas. Bergson se refería a las condiciones de vida para determinar la percepción del mundo. "Los objetos que rodean mi cuerpo reflejan la posible acción de mi cuerpo sobre ellos" (2006, p. 82). La misma propuesta acerca de la existencia de formas de vida y de tipos de percepción la encontramos en el análisis de Deleuze:

En resumen, la representación en general se divide en dos direcciones que difieren en naturaleza, en dos presencias puras que no se dejan representar: la de la percepción que nos introduce de golpe en la materia, la de memoria que nos introduce de golpe en el espíritu. Que ambas líneas se encuentren y se mezclen, una vez más, esa no es la cuestión. Esta mezcla es nuestra experiencia misma, nuestra representación. (1987, p. 23)

No obstante, en la tarea por controlar las formas de vida desde los regímenes escópicos, continuaron con el sentido de la religiosidad del arte, ya adoptado con anterioridad. Durante el siglo XIX, hubo un empeño sobre la noción de idea en el arte. La idea original de obra de arte, de connotaciones platónicas, se interpretó como una imagen de ensueño que se le aparece al hombre en circunstancias subliminales. El arte es una revelación de inspiración divina; esta representación se remonta al artista Raffaello Sanzio (1483-1520). Según nos enseña Pochat (2008), esta acentuación de la religiosidad fue seguida por el líder del Romanticismo Friedrich Schegel. El Romanticismo se consideró un fenómeno cultural europeo que se caracterizó por su oposición al modelo normativo de belleza del neoclasicismo.

Kant había investigado filosóficamente la esencia y la función del juicio estético, sus posibilidades y sus límites, y Schiller ha estudiado el significado moral de lo bello y del arte para el hombre y la sociedad: Herder abogó por una concepción expresivista del arte y la naturaleza: la obra de arte posee una forma orgánica que es capaz de reflejar 
tanto lo universal, lo ideal, como lo subjetivo, lo terrenal. En ella se equilibra la antinomia entre idea y realidad. Y los románticos subrayaron el aspecto religioso del sentimiento. (Pochat, 2008, p. 470)

La posición idealista kantiana tuvo su continuidad en el Romanticismo a través de la interpretación que hicieron del idealismo transcendental de Fitche (2006). Por esta vía idealista, llegaron a las vanguardias artísticas del siglo XX diversas características del Romanticismo. El arte comenzó a convertirse en un producto de la conciencia, un ejercicio de la manumisión del individuo y una creación de la libertad. Los románticos concedieron esta misión reveladora al arte sumando la estética con lo místico. Lo real y lo ideal se fusionan en la estética romántica en una unidad absoluta espiritual que se extiende sobre todas las cosas. Todo lo que construye el Romanticismo de Schelling (2004) sobre la armonía y la paz que genera la visión de lo sublime alcanza la contemporaneidad. También nos alcanza la figura del genio o la influencia del artista que destaca sobre el resto de los hombres y le permite representar cosas que ni él mismo consigue comprender su sentido.

La cultura moderna privilegió sobre otros factores la ciencia y la tecnología, las ideologías o las oscilaciones del gusto reflejadas en el mercado de consumo. De modo que los descubrimientos científicos, como la óptica, la perspectiva cartesiana o la invención de la fotografía dieron origen a regímenes escópicos que se diferenciaron en el tiempo de otros regímenes en los que dominaba la fuerza del compromiso político, la acción reivindicativa, las estrategias psicológicas o los estudios sociológicos sobre los hábitos de consumo. La aportación intelectual de Crary (2008, p. 309) va más lejos en estos aspectos, resaltando el protagonismo de los descubrimientos psicológicos durante el siglo XX como la ensoñación hipnagógica o la sugestión hipnótica, además de otras cuestiones de la personalidad humana y de sus tensiones psicológicas. Por su parte, Croce intitula otras identificaciones y confusiones del arte durante el siglo XVIII:

En la filosofía del siglo XVIII tenemos ejemplos de identificación y de confusión del arte con la religión y la filosofía que nos suministran Schelling y Hegel; Taine confunde el arte con las ciencias naturales; 
los veristas franceses lo barajan con la observación histórica y documentada; el formalismo de los herbatzianos confunde el arte con las matemáticas. (1938, p. 31)

Además, no podemos olvidar que la estética moderna se ha entendido casi siempre como la conquista de la visualidad pura. La controversia entre modernidad y posmodernidad precisamente radica en la defensa de una pureza formalista visual (Greenberg, 2005) frente a un arte posmoderno que rechaza todas las obligaciones impuestas por la racionalidad artística moderna (Danto, 2014). “Gran parte del arte contemporáneo no es estético en absoluto, pero en su lugar tiene el poder del significado y la posibilidad de la verdad, y de la interpretación depende que dichas cualidades afloren o no" (Danto, 2014, p. 152).

Todas estas caracterizaciones de los regímenes escópicos entran en conflicto con la perspectiva más materialista que el arte político funda en el mismo tiempo revolucionario de las vanguardias artísticas. "La violencia de la guerra acabó con la mayor parte de la voluntad artística” (Einstein 2008, p. 106). La Primera Guerra Mundial acabó con cierto espíritu innovador, experimental y de ruptura idealista. El idealismo artístico tributa una serie de propiedades inmutables y universales en el arte. Tras el idealismo se oculta la creencia sobre que todas las obras de arte poseen algo en común. La búsqueda de ese algo común (como una experiencia compartida con la obra de arte), en principio, es la misión de la filosofía, o más concretamente, de la estética. Esta idea perdura en el arte contemporáneo donde ya no existe el sentido neoplatónico furor divinus sive poeticus.

Los regímenes escópicos no nos descubren “cómo son las cosas”, por el contrario, y como por su parte nos ha demostrado Merleau-Ponty (2013), nos enseñan "cómo miramos las cosas". El objeto de arte consiste en dar visibilidad a esas cosas, perdiendo su propia visión como cosa en el mundo.

Basta con que yo vea una cosa para que sepa unirme a ella y alcanzarla, aunque no sepa cómo se hace esto en la máquina nerviosa. Mi cuerpo móvil cuenta en el mundo visible, forma parte de él, y por eso puedo dirigirlo en lo visible. Por lo demás, es verdad también que la visión está suspendida del movimiento. Solo se ve aquello que se mira. (p. 21) 
La modernidad artística buscó una ruptura total con el espíritu clásico del Renacimiento. Incluso se radicalizó abandonando el naturalismo y el realismo y encaminándose hacia la abstracción absoluta. El realismo es contrario al espíritu revolucionario del siglo XX. La visión realista vinculaba el arte al humanismo, a la mímesis y a la tradición, entendida como las conexiones con el pasado. El arte revolucionario ofrecerá una explicación del mundo desde la acción del artista, ahora considerado parte del plan del arte. El objetivo del arte moderno vendrá marcado por su función comunicativa. En este caso, su superioridad consiste en la capacidad de penetración de la información controlable.

\section{Conclusiones}

De todo lo expuesto, podemos concluir del modo siguiente:

1. Los estudios visuales actualmente revisan la noción de imagen y aportan ideas nuevas desde los discursos institucionalizados (en concreto de la estética, la historia del arte, la teoría del arte, la filosofía o los estudios culturales) y realizan una crítica sobre los aspectos residuales que estas disciplinas no abordaban desde sus metodologías de investigación. En los límites de las disciplinas implicadas, surge el avance teórico que nos lleva a la comprensión de las nuevas nociones que hemos analizado: la cultura visual, los objetos visuales, el esencialismo visual y los regímenes escópicos.

2. La cultura visual ha logrado un redescubrimiento de la experiencia frente a las imágenes que sobrepasa la lógica estructural del lenguaje en la explicación del mundo. Lo visual supone una liberación de la textualidad en cuanto puede fundamentar las proposiciones de verdad mediante medios extralingüísticos. Las imágenes se nos presentan ahora como organismos vivos autónomos de sus creadores que se abren en interpretaciones a los espectadores de acuerdo con sus formas de vida. La vivencia de estas imágenes es un acontecimiento importante que ahora reconocemos en distintos ámbitos de la actividad humana que van desde la ciencia y la tecnología a la fundación de creencias e ideologías. 
3. Las implicaciones categoriales de estos hallazgos visuales (los objetos visuales, el esencialismo visual o los regímenes escópicos) son decisivas para el entendimiento de la visualidad, pues establecen que la influencia de las imágenes reside en la conexión de estas con lo indeterminado de la realidad. Por ello, podemos solo observar lo representado en su contexto preestablecido. Goodman nos refiere incluso mundos que no existen, pero que vemos. A estos mundos le concedemos la categoría de realidad por las conexiones con nuestra forma de vida. Las mismas relaciones vitales han dado lugar a los regímenes escópicos, cuyo poder e influencia reside en las identificaciones $\mathrm{y}$ confusiones que provoca la visualidad en los hombres.

Para terminar, afirmamos que el logos deja de dominar las posibilidades expresivas de las imágenes, y al revés, en la cultura contemporánea la palabra depende de lo visual.

\section{Referencias}

Bal, M. (2003). Visual essentialism and the object of visual culture. Journal of Visual Culture, 2(1), 5-32. doi: 10.1177/147041290300200101.

Barthes, R. (1997). Sade, Fourier, Loyola. Madrid: Cátedra.

Barthes, R. (1999). El susurro del lenguaje: más allá de la palabra y la escritura. Barcelona: Paidós.

Benjamin, W. (1992). Sobre arte, técnica, linguagem e política. Lisboa: Relógio D’Agua Editores.

Bergson, H. (2006). Memória e vida. São Paulo: Martins Fontes.

Boehm, G. (2011a). ¿Más allá del lenguaje? Apuntes sobre la lógica de las imágenes. En A. García Varas (ed.), Filosofía de la imagen (pp. 87106). Salamanca: Universidad de Salamanca. 
Boehm, G. (2011b). El giro icónico. Una carta. Correspondencia entre Gottfried Boehm y W. J. Thomas Mitchell (I). En A. García Varas (ed.), Filosofía de la imagen (pp. 57-70). Salamanca: Universidad de Salamanca.

Bryson, N. (2005). Volver a mirar: cuatro ensayos sobre la pintura de naturalezas muertas. Madrid: Alianza.

Cappelletto, C. (2010). Neuroasthetics: Origns, perspetives, problems. En O. Pombo, S. di Marco y M. Pina (eds.), Neuroaesthetics: Can science explain art? (pp. 81-100). Lisboa: Fim de Século.

Crary, J. (2008). Suspensiones de la percepción: atención, espectáculo y cultura moderna. Madrid: Akal.

Croce, B. (1938). Breviario de estética: cuatro lecciones seguidas de dos ensayos y un apéndice. Buenos Aires: Espasa-Calpe.

Danto, A. C. (2014). Qué es el arte. Paidós: Barcelona.

Debord, G. (2010). La sociedad del espectáculo. Valencia: Pre-Textos.

Deleuze, G. (1987). El bergsonismo. Madrid: Cátedra.

Dickie, G. (2005). El círculo del arte. Barcelona: Paidós.

Einstein, C. (2008). El arte como revuelta: escritos sobre las vanguardias (19121933). Valencia: Lampreave/Millán.

Feyerabend, P. K. (1984). Wissenschaft als Kunst. Fráncfort: Suhrkamp Verlag.

Feyerabend, P. K. (2003). Tratado contra el método: esquema de una teoría anarquista del conocimiento. Madrid: Tecnos.

Fitche, J. G. (2006). Fundamento de toda la doctrina de la ciencia (1794). Pamplona: Juan Cruz Cruz. 
García Varas, A. (ed.) (2011). Filosofía de la imagen. Salamanca: Universidad de Salamanca.

Gombrich, E. H. (2014). Breve historia de la cultura. Barcelona: Península.

Goodman, N. (1976). Languages of art: An approach to a theory of symbols. Indianapolis: Hackett.

Goodman, N. (1990). Maneras de hacer mundos. Madrid: Visor.

Greenberg, C. (2005). Arte y cultura. Barcelona: Paidós.

Gumbrecht, H. U. (2004). Production of presence: What meaning cannot convey. Stanford: Stanford University Press.

Heidegger, M. (2012). Caminos de bosque. Madrid: Alianza.

Husserl, E. (2011). La idea de la fenomenología. Barcelona: Herder.

Jay, M. (2007). Ojos abatidos: la denigración de la visión en el pensamiento francés del siglo XX. Madrid: Akal.

Lyotard, J.-F. (2012). La condición posmoderna: informe sobre el saber. Madrid: Cátedra.

Merleau-Ponty, M. (2013). El ojo y el espíritu. Madrid: Trotta.

Mitchell, W.J. T. (2011a). ¿Qué es una imagen? En A. García Varas (ed.), Filosofía de la imagen (pp. 107-154). Salamanca: Universidad de Salamanca.

Mitchell, W.J. T (2011b). El giro pictorial. Una respuesta. Correspondencia entre Gottfried Boehm y W.J. Thomas Mitchell (II). En A. García Varas (ed.), Filosofía de la imagen (pp. 71-86). Salamanca: Universidad de Salamanca. 
Moxey, K. (2015). El tiempo de lo visual: la imagen en la historia. Buenos Aires: Sans Soleil Ediciones.

Pinotti, A. (2017). Story-Telling: Typologies of iconic narratives. En O. Pombo (ed.), Image in science and art (pp. 33-58). Lisboa: Fim de Século.

Pochat, G. (2008). Historia de la estética y de la teoría del arte. Madrid: Akal.

Pombo, O. (ed.) (2017). Image in science and art. Lisboa: Fim de Século.

Pombo, O., Marco S. di y Pina, M. (eds.) (2010). Neuroaesthetics: Can science explain art? Lisboa: Fim de Século.

Rancière, J. (2010). El espectador emancipado. Castellón: Ellago Ensayo.

Schelling, F. W. J. (2004). El "Discurso de la Academia": sobre la relación de las artes plásticas con la naturaleza. Madrid: Biblioteca Nueva.

Virilio, P. (1989). La máquina de visión. Madrid: Cátedra.

Wittgenstein, L. (1977). Investigaciones filosóficas. Barcelona: Crítica.

Wollen, P. (2006). El asalto a la nevera: reflexiones sobre la cultura del siglo $X X$. Madrid: Akal.

Wollheim, R. (1972). El arte y sus objetos. Barcelona: Seix Barral.

Zeki, S. (1999). Inner vision: An exploration of art and the brain. Oxford: Oxford University Press. 